\title{
Raça, racismo e saúde: a desigualdade social da distribuição do estresse
}

\author{
André Faro \\ Universidade Federal de Sergipe \\ Marcos Emanoel Pereira \\ Universidade Federal da Bahia
}

\begin{abstract}
Resumo
A presente revisão explora os conceitos de raça e racismo, delimitando particularidades quanto ao perfil de saúde de indivíduos ou grupos submetidos à discriminação ou preconceito racial. Além disso, pretende-se levantar evidências da relação entre racismo e saúde a partir dos estudos sobre o estresse. Apresenta-se a desigualdade social como um poderoso fator na causação de iniquidades em saúde, o que fomenta disparidades em relação à prevalência de estresse. Sendo o racismo um elemento criador e mantenedor de estressores no âmbito das relações sociais, discorre-se sobre como a discriminação racial implica limitações fundamentais na vida dos indivíduos, o que impacta incisivamente na quantidade de estresse experienciada. Enfim, procurouse sistematizar o conhecimento acerca das relações entre raça e saúde, investigando-se o impacto deletério do racismo sob o princípio da distribuição social do estresse.
\end{abstract}

Palavras-chave: estresse; identidade racial; preconceito racial; racismo; saúde.

\begin{abstract}
Race, racism and health: the social inequality of the distribution of stress. This review exploits the concepts of race and racism and defines particularities for the health profile of individuals or groups subject to discrimination or racial prejudice. In addition, we intend to seek evidences of the relationship between racism and health from the studies on stress. It presents social inequality as a powerful factor in the causality of health inequalities, which generates disparities in the stress prevalence. Racism is a creator and sustainer element of stressors in the context of social relations, and it explains how racial discrimination provokes fundamental limitations in the individuals' life, which impacts broadly on the amount of stress experienced. We tried to systematize knowledge about the relationship between race and health, investigating the deleterious impact of racism on the principle of social distribution of stress.
\end{abstract}

Keywords: health; racial identity; racial prejudice; racism; stress.

$I^{2}$ niquidades em saúde existem globalmente (Contrandiopoulos, 2006; Marmot, 2005), porém, peculiaridades da estruturação social tendem a revelar as diferentes facetas da desigualdade. Por menos desejável que isto seja, a iniquidade parece ser uma característica marcante em sociedades pautadas na racialização das relações sociais, nas quais a cor da pele geralmente surge associada à segregação de minorias e à discrepância no acesso aos recursos necessários para o desenvolvimento humano.

Contrariando a expectativa da equidade dos fatores de proteção ou risco à saúde, uma constante na dimensão de vida e morte das populações é a evidente disparidade das condições de saúde entre os diversos estratos sociais, a saber: membros de grupos minoritários possuem maior probabilidade de nascerem em ambientes socialmente desfavorecidos (Cardoso, Santos, \& Coimbra Júnior, 2005; Giscombé \& Lobel, 2005), apresentarem maiores dificuldades no seu desenvolvimento físico e psíquico
(Bynum, Burton, \& Best, 2007; Caldwell, Guthrie, \& Jackson, 2006) e vivenciarem intensamente a cronicidade de estressores sociais (Franklin \& Boyd-Franklin, 2000; Harrell, 2000; Lopes, 2005).

Os achados acima demonstrados, portanto, remetem à existência de desigualdades e iniquidades no campo da saúde de indivíduos e populações. Conceitualmente, o termo desigualdade social significa a ocupação de diferentes posições na estrutura social e, por consequência, na variabilidade do privilégio de acesso a bens e serviços com disponibilidade limitada no meio social. Embora usualmente se espere algum nível de desigualdade na distribuição dos recursos sociais, o tamanho da disparidade é que suscita análises mais aprofundadas acerca das causas da diferenciação, o que remete à existência de iniquidade.

A iniquidade constitui-se das desigualdades nos índices de saúde que são consideradas inaceitáveis por sua 
desproporcionalidade e/ou caráter de injustiça, o que reflete a extrapolação de diferenças biológicas na determinação da saúde e traz à pauta a distinção social de extratos populacionais mais e menos favorecidos na organização da sociedade. Tal panorama remete à necessidade de investigação dos fatores que elevam a exposição de um determinado extrato a condições deletérias ou elementos prejudiciais à saúde, ou seja, a iniquidade fomenta distintos padrões de vulnerabilização ao adoecimento e chance de morte a depender do grupo social que se enfatiza (Escorel, 2001).

Contemporaneamente, estudos mostram que a iniquidade impacta incisivamente sobre a saúde das minorias, cujo reflexo se evidencia através em seus mais altos índices de adoecimento físico e mental (Batista, 2002; Clark, Anderson, Clark, \& Williams, 1999; Kazarian, 2001; Pieterse \& Carter, 2007), o que leva a uma pior qualidade vida (Cruz, 2010; Nazroo \& Williams, 2006; Whitfield, Weidner, Clark, \& Anderson, 2003) e restrição no acesso às tecnologias em saúde (Souza, 2011; Whaley, 1998). Nesse sentido, pesquisas mostram que inúmeros fatores psicossociais fazem com que os indivíduos que compõem camadas minoritárias da população tendam a ser mais vulneráveis ao risco de morrer prematuramente ou serem acometidos por doenças graves (Chor \& Lima, 2005; Deaton, 2003; McDonough, Williams, House, \& Duncan, 1999; Oliveira, 2003).

Assentindo a posição de Nazroo e Williams (2006), entende-se que o impacto da desvantagem social é maior nas minorias, pois o espelho da imobilidade da estrutura social reside na razão entre a limitação de oportunidades de mudança e a maior exposição a fatores nocivos no curso de vida. Assim, as disparidades em saúde retratam a desigualdade social, o que ressalta a necessidade de maior aprofundamento por parte das investigações em psicologia social. O espectro desse conjunto de constatações é o fato de que a estrutura social coloca à margem grupos caracterizados por um amplo panorama de vulnerabilidades que, mesmo sendo históricas, mantêm-se como o centro das atenções no combate à desigualdade e promoção de saúde para as populações. Apesar de nas duas últimas décadas ter havido implemento substancial de ações afirmativas contra as iniquidades em saúde (Bastos, Celeste, Faerstein \& Barros, 2011; Marmot, 2005), na prática ainda não se percebem mudanças efetivas na determinação social da saúde das minorias (Adler \& Rehkopf, 2008; Shaw, Dorling, \& Smith, 2006), o que também se parece possível aplicar ao contexto brasileiro (Batista, 2002; Chor \& Lima, 2005; Cruz, 2010; Lopes, 2005; Oliveira, 2003; Souza, 2011; Souzas, 2005).

Nos estudos sobre as iniquidades em saúde, as disparidades em relação ao critério raça parecem ser consenso quanto ao seu papel crucial na compreensão do processo saúde-doença dos diversos estratos sociais (Chor \& Lima, 2005; Laguardia, 2004), especialmente enfatizado na análise da distribuição social do estresse. Logo, percebe-se que as minorias tendem a ser alvos mais frequentes de fatores estressores dos mais variados tipos (biológicos, psicológicos e sociais), o que impacta negativamente através da produção de um pior perfil de saúde, quando comparados aos grupos majoritários (McDonough et al., 1999; Schnittker \& McLeod, 2005).

Em consonância às ideias apresentadas até então, julga-se necessária a investigação acerca do impacto da dinâmica social sobre a saúde, isto é, considera-se pertinente a busca por entender o status de saúde de indivíduos e populações a partir de nuanças do contexto psicossocial. De modo especial, pelo fato da raça e/ ou etnia estarem intimamente relacionados com diversos outros aspectos sociais, tais como a pobreza e as disparidades em saúde (Batista, 2002; Eccleston, 2008; Krieger, 2003; Quintana, 2007; Schnittker \& McLeod, 2005;), entende-se que a análise das diferenças segundo a raça tem se mostrado como ponto crucial no delineamento de inúmeros estudos (Bastos et al., 2011; Geiger, 2006; Jones, 2007). Dessa forma, assumindo a condição de parâmetro norteador desta revisão de literatura, parte-se aqui do princípio que as diferenças dos perfis de saúde dos grupos sociais possuem implicação mais ampla que a própria definição de desigualdade. Elas estão imbricadas em processos psicossociais que influenciam marcantemente os determinantes da saúde, criando iniquidades na distribuição social do adoecimento, inclusive, na distribuição social do estresse.

Frente ao que foi exposto até o momento, o objetivo do presente estudo foi explorar os conceitos de raça e racismo, delimitando suas particularidades quanto ao perfil de saúde de grupos submetidos à discriminação ou preconceito racial e, em particular, levantar as evidências de impacto negativo sobre a saúde fornecidas pelas pesquisas sobre o estresse.

\section{Raça e saúde}

Lineu, em 1738, foi o primeiro pesquisador a fazer referência à cor de pele como um critério definidor das diferenças entre os seres humanos, distinguido as raças segundo alocações geográficas. Separando inicialmente em quatro ramos de espécies humanas, ele classificou a existência dos americanos, africanos, asiáticos e europeus. Embora tivesse feito apenas uma demarcação tópica acerca das diferenças, Lineu foi além dos critérios biológicos e associou características culturais a cada tipo humano: africanos como espertos e negligentes, americanos como obstinados e educados, asiáticos como rigorosos e avarentos e europeus como inventivos e descuidados. Com efeito, formulou-se a primeira atribuição sistemática e arbitrária de aspectos psicológicos e sociais aos indivíduos a partir do fenótipo observado (Oliveira, 2003).

Historicamente, a consideração da raça como ferramenta de estratificação social é um reflexo da centralidade desta característica nas sociedades ocidentais e, inclusive, na subjetividade dos indivíduos. No compasso de tal estratificação, os estudos que envolvem a perspectiva da psicologia social e o processo saúde-doença, com frequência recorrem à delimitação de grupos sociais para compreender como se desenvolvem e se instalam as disparidades em saúde.

A título de ilustração, historiadores mostraram que enquanto na Inglaterra os primeiros registros considerando a raça como uma questão censitária ocorreram no ano de 1991, nos EUA este tipo de informação já era coletada desde o primeiro censo, em 1790, estando registrada, na constituição americana daquela época, a hierarquia racial baseada no cálculo de três tipos de pessoas: brancos, negros (equivalendo a três quintos de uma pessoa branca) e os índios civilizados, desde que estes pagassem os impostos (os que não pagavam não eram considerados 
indivíduos) (Dion, 2003). A mudança de tais critérios ocorreu apenas no censo realizado em 1910, no qual foram abandonados os cálculos de racialidade, ficando instituídas raças a partir apenas do critério cor de pele e miscigenação familiar (Nazroo \& Williams, 2006).

No Brasil, Oliveira (2003) destaca que mesmo os abolicionistas não propalavam o combate às ideologias raciais, mantendo o paradoxo de serem a favor da libertação dos negros e posicionarem-se contra a imigração africana, sob o argumento implícito de um futurístico embranquecimento da população. Este contraste permaneceu bem visível na ordem da sociedade brasileira até a constituição de 1988, onde, enfim, foi retirada a lei acerca da proibição da imigração de africanos.

Atualmente o debate acerca das ordenações biológicas segundo a raça ou etnia é considerado estéril, tendo em vista a constatação do projeto genoma, que ratificou que não há fundamento genético para que sejam distintas as raças humanas (Geiger, 2006; Oliveira, 2003). Neste sentido, uma importante conclusão sobre a genética das populações é que a diferenciação genotípica não existe, pois os seres humanos compartilham mais de $99 \%$ do DNA e a cor da pele é apenas uma potencialidade mínima de distinção, injustificável para a extrapolação da hierarquização por meio de argumentos biologicistas (Chor \& Lima, 2005; Daniels \& Schulz, 2006; Laguardia, 2004). Diante disso, não havendo a priorização genética da raça, resta na análise de 'fatores além-biológicos' a busca por explicar a estruturação díspar das sociedades calcadas na cor da pele.

Pelo fato dos termos raça e etnia serem muitas vezes mencionados de forma indiferenciada, faz-se pertinente esclarecer os domínios de cada definição, pois a distinção que hoje se opera no âmbito científico se baseia nos aspectos socioculturais de um dado grupo (Quintana, 2007; Schnittker \& McLeod, 2005; Souzas, 2005). Seguindo as definições apontadas em Oliveira (2003), por etnia se depreende um grupo de indivíduos e/ou comunidades que se reconhecem como pertencentes à mesma origem gentílica, compartilhando traços culturais comuns através da história de sua existência, a qual remete a um passado coletivo comum, somado a alguma característica física ou cultural externa evidente. A raça, por sua vez, é utilizada para caracterizar traços biológicos herdados que diferenciam grupos humanos (i.e. traços faciais e cor de pele).

Em geral, a etnia é usada para designar culturalmente grupos humanos e assim distinguir o indivíduo por mútua identificação coletiva, enquanto que a raça se volta para a caracterização de indivíduo, progredindo para a noção de grupo por similaridade e não necessariamente compartilhamento de mútuo reconhecimento. No Brasil, como salienta Oliveira (2003), não é habitual se referir aos grupos sociais enquanto etnias, posto que para diversos ramos de ativismo contra a discriminação, o termo etnia serve para encobrir o preconceito e o racismo ainda existente. Desta feita, no âmbito da literatura científica brasileira, e por consequência neste trabalho, utilizar-se-á o termo raça como um equivalente ao termo etnia.

As classificações recentes de raça seguem a demanda da imigração de novos grupos de indivíduos em um determinado local, normatizada através de um mero critério de distinção demográfica (Nazroo \& Williams, 2006). Em outras palavras, o uso de categorias raciais, acima de comparações enquanto hierarquia entre tipos humanos é exclusivamente uma construção histórico-social; utilizada inapropriadamente em pseudoconclusões sobre a inferioridade das minorias (Daniels \& Schulz, 2006; Schnittker \& McLeod, 2005). A discriminação se insere em um suposto contexto de hierarquizações, sendo entendida como a expressão ou adoção de padrões de referência voltados para o próprio grupo, podendo também ser rejeição dos membros de outros grupos (Pereira, 2002). Particularmente, a discriminação racial cria limitações fundamentais na vida dos indivíduos, implicando em maiores ameaças contingentes e afetando o seu senso de integridade individual (Bianchi, Sea, Belgrave, \& Echeverry, 2002; Clark et al., 1999). No geral, a discriminação pode atuar como um fator restritivo no acesso a importantes recursos como educação, saúde, ocupação e habitação, isto por meio da segregação institucionalizada, além de impactar diretamente sobre a autocategorização por pertencer a um grupo desprivilegiado socialmente (Nazroo \& Williams, 2006; Souza, 2011).

Estudos variados nacionais e internacionais evidenciam as disparidades existentes quando se considera o critério raça, em especial a negra. Na sociedade norte-americana, Caldwell et al. (2006), Giscombé e Lobel (2005) e Shaw et al. (2006) concluíram que crianças negras apresentam índices de mortalidade mais altos que crianças brancas. No Brasil, Cardoso et al. (2005) constataram que crianças negras tinham maiores taxas de mortalidade quando comparadas às brancas e pardas. Constatações similares foram obtidas por Lopes (2005), que cunhou o termo "Desesperança de Vida ao Nascer" (p. 1.598), que indica a maior probabilidade de minorias étnicas/raciais vivenciarem situações prejudiciais ao seu desenvolvimento durante a vida e, com isso, anteciparem a morte. Sobre isso, estudos apontam que os negros, em geral, possuem maior histórico de adoecimento grave e/ou crônico ao longo da vida (Chor \& Lima, 2005; Eccleston, 2008; Whitfield et al., 2003 ), como também apresentam mais elevados riscos em doenças específicas como a hipertensão, diabetes, AIDS, tabagismo, alcoolismo, amputações, cegueira e doença renalcrônica (Batista, 2002; Geiger, 2006). Quanto à saúde mental em particular, os negros registram maiores índices de depressão e reduzidos índices de bem-estar psicológico e autoestima, além de maior exposição ao estresse crônico e maior prevalência de transtornos adaptativos comuns (Bianchi et al., 2002; Clark et al., 1999; Eccleston, 2008; Franklin-Jackson \& Carter, 2007; Jones, 2007; Pieterse \& Carter, 2007; Whaley, 1998).

Expondo uma interessante singularidade dos estudos que assumem a raça como variável explicativa para a saúde, Daniels e Schulz (2006) apontaram que as conclusões mais comuns destas pesquisas centram-se na seguinte expressão: "não-brancos", crianças ou adultos, exibem maiores índices de "a condição vulnerabilizante, doença ou qualquer fator deletério e incapacitante" quando comparados aos brancos, por causa da "variável que explica a maior exposição". Essa expressão da disparidade revela um aspecto basal na construção dos parâmetros de saúde e a explicação de piores índices em geral: a ideologia da branquitude.

Tal como as demais categorias raciais, a cor branca, traduzida através da branquitude, também foi construída 
socialmente, possuindo a característica de ser a categoria mais flexível e fluida nas propriedades de seus participantes, posto se ater à própria dinâmica social de quem é (ou não) privilegiado e seu status de superioridade. É uma categoria que serve como limite social para as distinções dos grupos, internalizando o significado da ausência de marcas físicas, da constituição do molde social e do reflexo da própria pureza racial (Daniels \& Schulz, 2006; Franklin \& Boyd-Franklin, 2000).

Complementando tais argumentos, Lima e Vala (2004a) demonstraram que em sociedades multirraciais a cor da pele tende a ser associada de forma racista à atribuição de sucesso e fracasso social aos indivíduos. Em estudo realizado no Brasil, através da identificação de sujeitos unicamente por fotos, os autores encontraram que quanto maior a inferência de sucesso, maior a probabilidade de o indivíduo ser descrito como mais branco/claro, isto em comparação aos indivíduos que denotaram insucesso social, que geralmente foram considerados mais negros/escuros. Desse modo, percebem-se efeitos sociais deletérios que parecem derivar do absolutismo da ideologia da branquitude (Souzas, 2005), mediante o qual se pretende o aperfeiçoamento cultural na medida em que o indivíduo se afasta da identidade negra e assimila valores ditos como pertencentes à superioridade branca.

Tendo em vista o amplo corpo de estudos que obtêm como conclusão a expressão citada por Daniels e Schulz (2006), é criada a ilusão de que as desvantagens sociais se devem ao critério da raça, como visto no embranquecimento do sucesso. Deste modo, as comparações que são feitas entre grupos nãobrancos e brancos pouco refletem a transcategorização de fatores socioeconômicos associados, nem dissociam o impacto isolado de questões sociais como o racismo e a saúde. Como ilustrações de tais assertivas, dados confirmam que as mulheres negras e pobres tem menor acesso à saúde no Brasil (Batista, 2002; Lopes, 2005; Oliveira, 2003) e mulheres negras americanas, mesmo que tenham melhor posição social, ainda denotam índices menores de saúde mental em comparação às brancas (Nazroo \& Williams, 2006).

Como ilustração da complexidade do lugar da raça na dinâmica social da saúde, estudos sobre Hipertensão Arterial Sistêmica (HAS) argumentam que a predisposição ao adoecimento de negros por HAS pode ser bastante influenciada por condições sociais e não se resume a maior suscetibilidade à doença por seletividade genética. Há na literatura médica achados que sugerem a maior predisponibilidade fisiológica de afrodescendentes à retenção de sal e contração de vasos, o que configura um dos principais preditores para o desenvolvimento da HAS em negros (Brown, 2006). Entretanto, Cooper et al. (1997) mostraram que apesar dos índices de HAS entre afroamericanos serem mais altos em relação às demais etnias que residem nos EUA, a prevalência da hipertensão entre negros da América Central é mais baixa que a dos afro-americanos e, em comparação a negros africanos, o índice entre esses últimos é menor que os de indivíduos brancos nos EUA. Os resultados indicaram, então, que a elevada prevalência de HAS na população negra americana existe provavelmente devido ao maior impacto de fatores psicossociais que aumentam a vulnerabilidade a este tipo de doença; de modo central, o estresse motivado pelo racismo.

Pelo visto, a saliência da variável raça nos estudos em saúde e, em particular no estresse, deve-se ao fato de que há consistência empírica ao se afirmar que a raça apresenta um impacto independente de outras características usualmente listadas como sociodemográficas, pois, mesmo quando controlados os efeitos das variáveis socioeconômicas, tende a persistir o efeito da raça como modulador da saúde (Batista, 2002; Chor \& Lima, 2005; Eccleston, 2008; Geiger, 2006; Schnittker \& McLeod, 2005).

Enfim, percebe-se que a utilização da raça enquanto critério de distinção biológica, em comparações com o padrão branco, não é consistente com o arcabouço teórico e empírico na literatura contemporânea das ciências humanas e sociais (Laguardia, 2004), criando, na ausência de justificações que considerem a interseccionalidade da saúde (Mullings \& Schulz, 2006), uma lacuna explicativa que permite um amplo espectro de pseudo-teorizações fundamentadas na diferenciação biológica e valorativa das raças. É neste espaço que modelos teóricos, tal como o estresse, voltam-se para a investigação do impacto de fenômenos sociais sobre a saúde, tal como o racismo, para que se possa tentar compreender como a probabilidade ao adoecimento tende a ser resultante de dinâmicas sociais que marcam física e subjetivamente os indivíduos.

\section{Racismo e saúde: achados a partir da teoria do estresse}

Atualmente, a categorização racial utilizada nos estudos sobre a saúde se dá exclusivamente como uma construção histórico-social que intenta compreender o porquê das distintas realidades de adoecimento exibidas pelos diferentes grupos raciais, em especial das minorias (Bastos et al., 2011; Daniels \& Schulz, 2006; Schnittker \& McLeod, 2005). Deste modo, os perfis de saúde refletem uma implicação mais ampla que a própria constatação das disparidades segundo as raças; ou seja, os índices gerais da saúde mascaram o impacto velado de sociedades regidas pelo princípio da discriminação (Chor \& Lima, 2005; Geiger, 2006). Logo, é possível conceber que a saúde das minorias raciais está patenteada pela iniquidade, vista através da concentração de poder, privilégios e recursos que submetem indivíduos a uma realidade de mais frequentes experiências estressoras, limitada possibilidade de transformação social e menor capacidade de manejo do estresse (Krieger, 2003; Shaw et al., 2006).

Restringindo-se ao racismo e seus efeitos deletérios sobre a saúde, Harrell (2000) conceituou o estresse como relações entre indivíduos ou grupos e seu ambiente, das quais emergem significações da dinâmica do racismo, que são percebidas como algo que excede ou sobrecarrega os recursos individuais ou coletivos disponíveis para a adaptação, ou que ainda ameaçam a autopercepção de bem-estar psicológico. Com esse parâmetro, é sabido que a discriminação racial cria limitações fundamentais na vida dos indivíduos, implicando em maiores ameaças diretas ou contingentes, o que afeta o senso de integridade individual e impacta incisivamente sobre a quantidade de estresse experienciada (Bastos et al., 2011; Clark et al., 1999; Franklin \& Boyd-Franklin, 2000; Townsend \& Belgrave, 2009). 
Dentre as formas de discriminação mais conhecidas, o racismo é frequentemente relacionado nos estudos envolvendo a saúde das populações, sendo incorporado por diversos modelos enquanto variável explicativa do status de saúde (Caldwell et al, 2006; Clark et al., 1999; Geiger, 2006; Mullings \& Schulz, 2006; Nazroo \& Williams, 2006; Pieterse \& Carter, 2007; Whaley, 1998). Por definição, o racismo é entendido como crenças, atitudes e conformações institucionais que tendem a denegrir, subjugar e excluir grupos e pessoas em virtude de caracteres fenotípicos e/ou afiliação étnica (Clark et al., 1999). Como descreveram Lima e Vala (2004b), o racismo envolve uma rede ampla de aspectos para sua caracterização: é um processo de hierarquização, discriminação e exclusão de um grupo, ou mesmo um componente deste, que é distinto dos demais por possuir alguma marca física externa (real ou imaginária) que, no olhar do outro, associa-se a alguma característica subjetiva. Empreende-se, por conseguinte, uma redução do repertório sociocultural e psicológico às qualidades biológicas, não somente em nível individual, mas também institucional, político e cultural.

É visto na literatura que em virtude de um passado de opressão e submissão social, o racismo reflete a realidade do acúmulo de estressores crônicos que se somam à cotidianidade da vida da população minoritária, a qual, frequentemente, traz estressores agudos e especialmente particularizados em contextos discriminatórios (Bynum et al., 2007; Clark et al., 1999; Whaley, 1998). Dito de outra forma, a vulnerabilidade das minorias raciais é também compreendida sob a luz do acúmulo de estressores e, com isso, o estresse é colocado como um fator explicativo para o impacto do racismo sobre a saúde (Caldwell et al., 2006; Franklin-Jackson \& Carter, 2007; Schnittker \& McLeod, 2005).

O racismo fornece o contexto necessário para a criação e manutenção de estereótipos, preconceitos e discriminação, visto ser fomentado por um histórico de injustiça e sustentação da desigualdade, estando ligado a estressores persistentes que minam cronicamente a capacidade de adaptação, ajuste social e sensação de bem-estar dos indivíduos (Harrell, 2000). Na tentativa de delinear um modelo compreensivo de como o racismo afeta a saúde, para Krieger (2003) o racismo impacta em seis dimensões: 1) Acentua a escassez de recursos econômicos e sociais; 2) Causa maior exposição a fatores nocivos e tóxicos, como por exemplo, empregos de menor qualificação e maior risco; 3) É facilitador de conjecturas sociais que provocam danos à saúde; 4) Provê inadequados cuidados e acesso à saúde; 5) Potencializa a ocorrência de experiências agressoras motivadas pela discriminação ou violência; 6) Induzem com maior frequência a autopercepção de saúde de indivíduos expostos ao racismo como deteriorada. Tais padrões de discriminação podem ser situados tanto em aspectos materiais (discriminação institucional ou interpessoal flagrante), como subjetivos, através da internalização do racismo.

No Brasil, por exemplo, uma representativa constatação é que os negros vivem menos que os brancos, tal como se observara há séculos, mantendo uma disparidade proporcional ao período da escravidão (Oliveira, 2003). Uma das possíveis explicações para isso é que quando comparados aos brancos, os não-brancos são expostos a estressores específicos devido a sua alocação social, o que no decorrer da vida ocasiona a submissão a estados de estresse crônicos, minando a capacidade de adaptação e predispondo a doenças e à morte prematura, isto por serem vítimas mais frequentes de crimes ou pela ativação neurofisiológica prolongada, o que lesiona funções orgânicas (Franklin-Jackson \& Carter, 2007; Oliveira, 2003; Pieterse \& Carter, 2007; Santos, 2010; Whaley, 1998).

Embora pareça estar claramente documentada a associação entre raça e estresse (Geiger, 2006; Nazroo \& Williams, 2006; Townsend \& Belgrave, 2009), o link causal carece de maior aprofundamento por dois motivos: usualmente a raça é analisada de modo concomitante a outras variáveis sociais, o que dificulta distinguir o poder específico da categorização racial sobre o estresse (Krieger, 2003) e seu impacto interativo com outras variáveis, ou seja, o quanto contribui de modo isolado para a medida do estresse, merece maior aprofundamento (Schulz, Freundenberg, \& Daniels, 2006). Assim, em paridade com o estado atual de teoria do estresse, o estabelecimento de relações explicativas é um questionamento também pertinente à relação entre raça e estresse (Adler \& Rehkopf, 2008; Clark et al., 1999; Santos, 2010; Schwartz \& Meyer, 2010).

Kazarian (2001) defendeu que a ideologia racista serve ao propósito de sustentar e justificar a discriminação racial oriunda das relações institucionais e intergrupais. Nesta linha, para Nazroo e Williams (2006) o impacto do racismo sobre a saúde repousa em três eixos: a desvantagem econômica que é comum aos grupos discriminados, o senso depreciativo de se perceber como membro de um grupo desprezado e, por fim, na ameaça constante de ser vítima do racismo. Com efeito, pode-se explorar a dinâmica subjetiva do racismo sob o prisma de dois fatores precípuos: a identidade racial e a ameaça permanente ao bem-estar.

Não existe, na atualidade, um padrão objetivo para o racismo; antes de tudo, ele é uma experiência subjetiva (Franklin \& Boyd-Franklin, 2000). A carência de conhecimento sobre este aspecto se torna problemática quando, no geral, o que se observa é que as surveys buscam levantar experiências de discriminação e a sua frequência, mas não acessam o significado particular da discriminação sobre o desenvolvimento do indivíduo ao longo da vida (Schnittker \& McLeod, 2005), espaço onde se inserem as propostas de explicação da psicologia social aplicada à saúde (Santos, 2010).

Antes da instituição das normas antirracistas, a localização do agente agressor tinha maior probabilidade de ser direta, favorecendo o combate às expressões discriminatórias. Com as novas formas de expressão do racismo que são apontadas na literatura, predominantemente subliminares e interpessoais (Lima \& Vala, 2004b; Pereira, 2002), torna-se ainda mais complexa a investigação do seu impacto sobre o bem-estar e saúde dos indivíduos, predispondo ao efeito acumulativo dos estressores sobre a saúde (Santos, 2010). Como destacou Harrell (2000), o julgamento subjetivo da experiência de racismo é um ponto crítico para a compreensão da relação entre ser vítima de racismo e o seu bem-estar. Com efeito, não é incomum o questionamento da experiência, retornando a culpa para a vítima, esta devendo provar que foi discriminada e validar a significância 
da sua percepção (Clark et al., 1999). Tal condição cria a situação da "my-perception-against-yours" (Harrell, 2000, p. 44) (minha percepção contra a sua/de vocês), incidindo na criação e reforço de rótulos sociais, tais como paranóicos, manipuladores ou supersensíveis, direcionados aos sujeitos que se sentem alvo de discriminação.

A respeito da identidade racial, que é apreendida enquanto um mediador do estresse, Utsey, Chae, Brown e Kelly (2002) apresentam-na como um conjunto de ideias e valores, comportamentos e atitudes que são reconhecidos como compartilhados pela autocategorização de determinados indivíduos como pertencentes a grupos, distinguindo-os dos demais grupos sociais. Importante pontuar que sem se fazer referência a uma característica em si, tal como a raça, a definição de identidade social significa a percepção subjetiva de indivíduos acerca das diferenças intergrupais, assumindo como próprias reações coletivas frente às situações sociais baseadas no reconhecimento de grupos de pertença. Há, nesse contorno, a busca pelo desenvolvimento de um quadro de valores e atitudes que o caracterizem como semelhante aos participantes do grupo, ao mesmo tempo em que demarca os limites entre o próprio grupo e os demais (Quintana, 2007). Deste modo, independente da ligação da identidade social a um atributo de discriminação, o cerne do conceito de identidade mantém a noção de pertencimento como critério fundamental do estabelecimento da identidade social de um determinado grupo (Caldwell et al., 2006); nesta discussão, a raça.

Na literatura acerca da identidade racial, tem-se constatado que a repetição da exposição ao racismo no âmbito de um grupo social tende a desafiar a capacidade de o indivíduo manter seu bem-estar e saúde (Eccleston, 2008; Utsey et al., 2002), sendo a flexibilidade e consistência da identidade uma condição positiva para o enfrentamento (Quintana, 2007; Pillay, 2005). Nesta direção, pesquisas têm encontrado correlações entre a identidade racial e a saúde. Schnittker e McLeod (2005), Franklin-Jackson \& Carter (2007) e Pillay (2005) relataram achados que indicam que altos níveis de autoestima, bem-estar psicológico e autopercepção de saúde mantém uma correlação positiva como escores em identidade racial. Já Caldwell et al. (2006) apontaram que identidades mais integradas tendem a lidar melhor com situações adversas ligadas à discriminação e racismo e, em âmbito nacional, Bianchi et al. (2002) encontraram que a identidade racial foi um preditor de elevada autoestima entre negros, como também maior consciência acerca do racismo.

No que se refere à saúde e ao racismo, acredita-se que a identidade racial enraíza aspectos individuais que provêm uma melhor estruturação do indivíduo, isto por meio de uma noção mais ampla de compartilhamento racial e cultural, da atribuição de significado e do senso de visão de mundo, além de oferecer um sistema de referência para se orientar frente aos desígnios do meio social (Harrell, 2000; Pillay, 2005). Com isso, a identidade racial parece fornecer uma poderosa defesa para amortecer o efeito do estresse motivado pelo racismo (Bianchi et al., 2002; Caldwell et al., 2006; Franklin-Jackson \& Carter, 2007; Quintana, 2007).

Em um estudo específico sobre a identidade racial, o estresse derivado do racismo e a qualidade de vida de negros, latinos e asiáticos norte-americanos, Utsey et al. (2002) encontraram que escores mais altos em identidade são o principal preditor de qualidade de vida junto aos negros, em comparação a asiáticos e latinos. No tocante ao racismo, ficou clara a relação entre o racismo e menores escores em qualidade de vida, entretanto, a identidade racial apareceu como um fator mediador dessa relação, compensando efeitos isolados da experiência de racismo. Outro dado importante é que os negros, apesar de relatarem maior exposição a situações de racismo, apresentaram índices mais altos de bem-estar comparados aos outros grupos. Tal achado corrobora o pressuposto Harrell (2000), que acredita que negros experienciam situações estressoras por racismo e discriminação com maior frequência quando equiparados a outras minorias. Sobre a identidade racial e o seu papel mediador, o achado reforça $\mathrm{o}$ argumento que identidades mais consistentes favorecem a minimização do estresse e, consequentemente, a manutenção do bem-estar e a saúde, mesmo diante da experiência flagrante de ser alvo de discriminação racial (Bianchi et al., 2002; Caldwell et al., 2006; Eccleston, 2008; Franklin \& Boyd-Franklin, 2000; Quintana, 2007).

Importa destacar que uma função essencial da identidade racial em relação à saúde parece ligar-se ao fato de que, mantendo uma maior integração com seu grupo de pertença, é disponibilizado ao indivíduo melhores formas de lidar com o impacto do racismo, posto a possibilidade de buscar suporte social entre os pares e assim atenuar as consequências da discriminação (Pillay, 2005). Deste modo, os sujeitos utilizam-se da legitimação intragrupal e o compartilhamento de experiências como meios reparadores da ferida aberta, todavia nem sempre implícita, do racismo.

Finalmente, viu-se que em virtude da raça as minorias tendem a ser mais expostas a estressores específicos - tais como os ligados à discriminação, o preconceito e a segregação social -, reforçando a noção de desigualdade na distribuição social do estresse. Porém, é válido apontar que as diferenças individuais na capacidade de adaptação psicossocial podem imprimir variações nas formas de avaliar e lidar com os estressores - a exemplo da mediação da identidade racial -, alterando o desfecho do estresse e revelando seu papel como importante motivo para a variabilidade adaptativa frente à exposição cotidiana aos estressores.

\section{Considerações finais}

Mediante a breve revisão aqui realizada e à luz dos objetivos pretendidos, acredita-se que a psicologia social aplicada à saúde, através dos estudos sobre o estresse, pode fornecer indícios para a compreensão de como os determinantes sociais da saúde afetam o nível de ajustamento de indivíduos e grupos minoritários, interligando aspectos objetivos da realidade social, como a desigualdade socioeconômica, a elucidação dos processos de subjetivação e enfrentamento da racialização social. Além disso, os achados oriundos das pesquisas sobre o estresse mostram indícios que há a distribuição social desigual das experiências estressoras conforme a raça, principalmente quando elas se associam a situações de racismo, cujos efeitos deletérios parecem configurá-las como determinantes psicossociais da saúde. 
Como fora mencionado por diferentes autores (Bastos et al., 2011; Chor \& Lima, 2005; Harrell, 2000), embora existam inúmeros levantamentos acerca do 'fator' raça nas pesquisas científicas, pouco se aprofundou a respeito das múltiplas formas do impacto do racismo na saúde dos indivíduos alvo. Logo, o estabelecimento de modelos multidimensionais se mostra como um campo essencial de análise do racismo e da saúde, no intento de evidenciar os mecanismos psíquicos e psicossociais que são mobilizados frente ao desafio de ser diverso em uma sociedade xenofóbica. Nesse ínterim, os estudos comprovando a relação entre o estresse e a saúde parecem estar consolidados enquanto sua relevância social, porém o efeito dos processos intrínsecos da transcategorização e funcionamento da capacidade de adaptação psicossocial se apresentam como importantes contribuições para o conhecimento, em especial no que se refere à raça, tendo em vista a dita centralidade na vida dos indivíduos.

Esta revisão apresenta como principal limitação o fato de somente ter explorado as evidências de relação entre o racismo, o estresse e a saúde, não adentrando com profundidade, às vicissitudes do processo de enfrentamento e adaptação psicossocial, tidos como elemento-chave para se compreender a variabilidade intra e intergrupal na exposição ao estresse (Schwartz \& Meyer, 2010). Sendo assim, dentre os possíveis delineamentos de pesquisas, desenhos que mapeiem, por exemplo, o papel da identidade racial e o seu efeito sobre o perfil de saúde na população negra brasileira podem contribuir na explicação de como os processos intrasubjetivos, intersubjetivos e intergrupais colaboram para o enfrentamento de situações estressógenas. Com este intuito, buscar-se-á conhecer de que modo os mecanismos psicossociais de adaptação funcionam como mediadores da relação entre o racismo e o estresse.

É pertinente ressaltar a carência de estudos relacionados ao estresse e ao racismo em âmbito nacional. Para esta revisão, embora se tenha buscado artigos científicos em importantes bases de dados de periódicos produzidos no Brasil (SciELO e PePsic), não foram encontradas pesquisas que objetivassem investigar a relação 'estresse x racismo x saúde'. Assim, consoante às recomendações de Bastos et al (2011), ocorre que, à despeito de se conhecer a relevância da interface entre a discriminação e a saúde, ainda são poucos os estudos conduzidos nacionalmente, especialmente no caso do estresse, sendo necessários investimentos teóricos e empíricos para que se possa melhor esclarecer, por exemplo, a caracterização dos estressores e dos modos de enfrentamento mais utilizados pelos indivíduos diante de situações de racismo ou segregação social. Tais investigações podem subsidiar ações voltadas para o manejo do estresse e a prevenção de desfechos negativos sobre a saúde, como também favorecer ao planejamento de intervenções no formato de políticas públicas de saúde para o combate à discriminação racial.

Por fim, as relações entre raça, racismo, estresse e o seu impacto sobre a saúde exibem pertinência enquanto objetos de estudo da psicologia social aplicada à saúde, pois, inseridos em uma sociedade maquiada pela igualdade retórica, grupos minoritários são alvo de micro e macro-agressões cotidianas que minam o bem-estar psicológico e a saúde dos indivíduos, sustentando o hiato entre o discurso democrático igualitário e a realidade social.

\section{Referências}

Adler, N. E., \& Rehkopf, D. H. (2008). U.S. disparities in health: descriptions, causes, and mechanisms. Annual Review of Public Health, 29, 235-252.

Bastos, J. L, Celeste, R. K., Faerstein, E., \& Barros, A. J. D. (2011). Discriminação racial e saúde: uma revisão sistemática de escalas com foco em suas propriedades psicométricas. Saúde \& Transformação Social, 1(2), 4-16.

Batista, L. E. (2002). Mulheres e homens negros: saúde, doença e morte (Tese de doutorado não publicada). Universidade Estadual Paulista, Araraquara, São Paulo.

Bianchi, F. T., Sea, M. C.; Belgrave, F. Z, \& Echeverry, J. J. (2002). Racial identity and self-esteem among black brazilian men: race matters in Brazil too! Cultural Diversity and Ethnic Minority Psychology, 8(2), 157-169.

Brown, M. J. (2006). Hypertension and ethnic group. British Medical Journal, $332,833-836$.

Bynum, M. S., Burton, E. T., \& Best, C. (2007). Racism experiences and psychological functioning in african americam college freshmen: is racial socialization a buffer? Cultural Diversity and Ethnic Minority Psychology, 13(1), 64-71.

Caldwell, C. H., Guthrie, B. J., \& Jackson, J. S. (2006). Identity development, discrimination, and psychological well-being among african american na caribbean black adolescents. In A. J. Schulz \& L. Mullings (Orgs.), Gender, Race, Classe, \& Health: intersectional approaches (pp. 163-91). São Francisco: Jossey-Bass.

Cardoso, A. M., Santos, R. V., \& Coimbra Júnior, C. E. A. (2005). Mortalidade infantil segundo raça/cor no Brasil: o que dizem os sistemas nacionais de informação? Cadernos de Saúde Pública, 21(5), 1602-1608

Chor, D., \& Lima, C. R. A. (2005). Aspectos epidemiológicos das desigualdades raciais em saúde no Brasil. Cadernos de Saúde Pública, 21 (5), 1586-1594.

Clark, R., Anderson, N. B., Clark, V. R., \& Williams, D. R. (1999). Racism as a stressor for african americans: a biopsychosocial model. American Psychologist, 54, 805-816.

Contrandiopoulos, A. P. (2006). Élements pour une topographie du concept de santé et ses determinants. Ruptures, 11(1), 86-99.

Cooper, R., Rotimi, C., Ataman, S., McGee, D., Osotimehin, B., Kadiri, S., ... Wilks, R. (1997). The prevalence of hypertension in seven populations of west african origin. American Journal of Public Health, 87, 160-168.

Cruz, I. C. F. (2010). Saúde da população negra: a construção da equidade no SUS pela implementação da Política Nacional de Saúde Integral da População Negra. Online Brazilian Journal of Nursing 9(3). Recuperado de http://www. objnursing.uff.br/index.php/nursing/article/view/j.1676-4285.2010.3194

Daniels, J., \& Schulz, A. J. (2006). Constructing whiteness inhealth disparities research. In A. J. Schulz \& L. Mullings (Orgs.), Gender, Race, Classe, \& Health: intersectional approaches (pp. 89-130). São Francisco: Jossey-Bass.

Deaton, A. (2003). Health, inequality, and economic development. Journal of Economic Literature, 41(1), 113-58.

Dion, K. L. (2003). Prejudice, racism, and discrimination. In T. Millon \& M. J. Lerner (Orgs.), Handbook of Psychology: personality and social psychology (Vol. 5, pp. 507-536). Hoboken, New Jersey: John Wiley \& Sons.

Eccleston, C. P. (2008). The psychological and physical health effects of stigma: the role of self-threats. Social and Personality Psychology Compass, 2, 1-12.

Escorel, S. (2001). Os dilemas da equidade em saúde: aspectos conceituais. Recuperado de http://biblioteca.planejamento.gov.br/biblioteca-tematica-1/ textos/saude-epidemias-xcampanhas-dados-descobertas/texto-83-2013-osdilemas-da-equidade-em-saude-aspectos-conceituais.pdf

Franklin, A. J., \& Boyd-Franklin, N. (2000). Invisibility syndrome: a clinical model towards understanding the effects of racism upon african american males. American Journal of Orthopsychiatry, 70(1), 33-41.

Franklin-Jackson, D., \& Carter, R. T. (2007). The relationships between racerelated stress, racial identity, and mental health for black Americans. Journal 
of Black Psychology, 33, 5-26.

Geiger, H. J. (2006). Health disparities: what do we know? What do we need to know? What should we do? In A. J. Schulz \& L. Mullings (Orgs.), Gender, Race, Classe, \& Health: intersectional approaches (pp. 261-288). São Francisco: Jossey-Bass.

Giscombé, C. L., \& Lobel, M. (2005). Explaining disproportionately high rates of adverse birth outcomes among african americans: the impact of stress, racism, and related factores in pregnancy. Psychological Bulletin, 131(5), 662-683.

Harrell, S. P. (2000). A multidimensional conceptualization of racism-related stress: implications for the well-being of people of color. American Journal of Orthopsychiatry, 70, 42-57.

Jones, J. M. (2007). Exposure to chronic community violence: resilience in African American children. Journal of Black Psychology, 33, 125-149.

Kazarian, S. S. (2001). Health issues in north american people of american heritage. In S. S. Kazarian \& D. R. Evans(Orgs.), Handbook of cultural health psychology (pp. 324-343). San Diego, California: Academic Press.

Krieger, N. (2003). Does racism harm health? Did child abuse exist before 1962 ? On explicit questions, critical science, and current controversies: an ecosocial perspective. American Journal of Public Health, 93(2), 194-199.

Laguardia, J. (2004). O uso da variável "raça' na pesquisa em saúde. Physis, 14(2), 197-234.

Lima, M. E. O., \&Vala, J. (2004a). Sucesso social, branqueamento e racismo. Psicologia: Teoria e Pesquisa, 20(1), 11-19.

Lima, M. E. O., \& Vala, J. (2004b). As novas formas de expressão do preconceito e do racismo. Estudos de Psicologia (Natal), 9, 401-412.

Lopes, F. (2005). Para além da barreira dos números: desigualdades raciais e saúde. Cadernos de Saúde Pública ,21(5), 1595-1601.

Marmot, M. (2005). Social determinants of health inequalities. The Lancet, 365, 1099-104.

McDonough, P., Williams, D. R., House, J. S., \& Duncan, G. J. (1999). Gender and the socioeconomic gradient in mortality. Journal of Health and Social Behavior, 40(1), 17-31.

Mullings, L., \& Schulz, A. J. (2006). Intersectionality and health: an introduction. In A. J. Schulz. \& L. Mullings (Orgs.), Gender, Race, Classe, \& Health: intersectional approaches (pp. 3-20). São Francisco: Jossey-Bass.

Nazroo, J. Y., \& Williams, D. R, (2006). The social determination of ethnic/ racial inequalities in health. In M. Marmot \& R. G. Wilkinson (Orgs.), Social determinants of health ( $2^{\underline{a}}$ ed, pp. 238-66). Nova Iorque: Oxford University Press.

Oliveira, F. (2003). A saúde da população negra no Brasil. Brasília: Organização Panamericana de Saúde.
Pereira, M. E. (2002). Psicologia social dos estereótipos. São Paulo: Pedagógica Universitária.

Pieterse, A. L., \& Carter, R. T. (2007). An examination of the relationship between general life stress, racism-related stress, and psychological health among black men. Journal of Counseling Psychology, 54(1), 101-109.

Pillay, Y. (2005). Racial identity as a predictor of the psychological health of african american students at a predominantly white university. Journal of Black Psychology, 31, 46-66.

Quintana, S. M. (2007). Racial and ethnic identity: developmental perspectives and research. Journal of Counseling Psychology,54(3), 259-270.

Santos, A. F. (2010). Determinantes psicossociais da capacidade adaptativa: um modelo teórico para o estresse (Tese de doutorado não publicada). Universidade Federal da Bahia, Salvador.

Schnittker, J., \& McLeod, J. D. (2005). The social psychology of health disparities. Annual Review of Sociology, 31, 75-103.

Schulz, A. J., Freundenberg, N., \& Daniels, A. J. (2006). Intersections of race, class, and gender in public health interventions. In A. J. Schulz. \& L. Mullings (Orgs.), Gender, Race, Classe, \& Health: intersectional approaches (pp. 371-393). São Francisco: Jossey-Bass.

Schwartz, S., \& Meyer, I. H. (2010). Mental health disparities research: the impact of within and between group analyses on tests of social stress hypotheses. Social Science \& Medicine, 70, 1111-1118.

Shaw, M., Dorling, D., \& Smith, G. D. (2006). Poverty, social exclusion, and minorities. In M. Marmot \& R. G. Wilkinson (Orgs.), Social determinants of health (2 $2^{\mathrm{a}}$ ed., pp. 196-223). Nova Iorque: Oxford University Press.

Souza, A. S. (2011). Racismo institucional: para compreender o conceito. Revista da Associação Brasileira de Pesquisadores(as) Negros(as), 1(3), 77-87.

Souzas, R. (2005). A saúde da população negra: uma questão de direito e equidade. Revista Educação Popular (Uberlândia), 4, 94-102.

Townsend, T. G., \& Belgrave, F. Z. (2009). Eliminating health disparities: challenges for african american psychologists. Journal of Black Psychology, 35(2), 146-153.

Utsey, S. O., Chae, M. H., Brown, C. F, \& Kelly, D. (2002). Effect of ethnic group membership on ethnic identity, race-related stress, and quality of life. Cultural Diversity \& Ethnic Minority Psychology, 8(4), 366-377.

Whaley, A. L. (1998). Racism in the provision of mental health services: a socialcognitive analysis. American Journal of Orthopsychiatry, 68(1), 47-57.

Whitfield, K. E., Weidner, G., Clark, R., \& Anderson, N. B. (2003). Cultural aspects of health psychology. In A. M. Nezu, C. M. Nezu, \& P. A. Geller (Orgs.), Handbook of Psychology: Health Psychology (pp. 27-50). Hoboken, New Jersey: John Wiley \& Sons.

André Faro, doutor em Psicologia Social pela Universidade Federal da Bahia, é professor da Universidade Federal de Sergipe. Bolsista de Desenvolvimento Científico Regional (DCR - CNPq) e pela Fundação de Amparo à Pesquisa e à Inovação Tecnológica do Estado de Sergipe (FAPITEC/SE). Endereço para correspondência: Avenida Sílvio Teixeira, no 691/ 1402, Jardins, Aracaju-SE. CEP: 49025-100. Telefone: (79)8103-6627. E-mail: andrefaro@superig.com.br Marcos Emanoel Pereira, doutor em Psicologia Social pela Universidade Federal do Rio de Janeiro e pósdoutor pela Universidade Complutense de Madrid e pela Universidade de Cambridge, é professor Associado na Universidade Federal da Bahia. E-mail: memanoel@gmail.com 